\title{
Safety and effectiveness of ferric citrate hydrate in serum phosphorus management of patients with chronic kidney disease: a long-term, real-world, observational, post-marketing surveillance study
}

\author{
Keitaro Yokoyama ${ }^{1,5} \cdot$ Teruo Hashimoto $^{2} \cdot$ Yuri Okuda $^{2} \cdot$ Yu Matsumoto ${ }^{2} \cdot$ Kyoko Ito $^{3} \cdot$ Ryoichi Yamada $^{2}$. \\ Hiroyuki Susai ${ }^{2} \cdot$ Noriaki Nishino $^{4}$
}

Received: 8 November 2021 / Accepted: 19 February 2022 / Published online: 8 March 2022

(c) The Author(s) 2022

\begin{abstract}
Background Ferric citrate hydrate (FC) is an oral iron-based phosphate binder that is used to treat hyperphosphatemia in patients with chronic kidney disease (CKD). This post-marketing surveillance study was performed to investigate the longterm safety and effectiveness of FC.

Methods This prospective, multicenter, observational post-marketing surveillance study was performed in a real-world setting in Japan. The study involved CKD patients with hyperphosphatemia receiving FC who were undergoing either hemodialysis or peritoneal dialysis or were non-dialysis-dependent. Adverse drug reactions, iron- and erythrocyte-related parameters (i.e., levels of serum ferritin, transferrin saturation, and hemoglobin), and serum levels of phosphorus, corrected calcium, and intact parathyroid hormone were monitored for up to 104 weeks.

Results Safety was evaluated in 2723 patients. Of these patients, $20.5 \%$ discontinued FC because of adverse events, and $3.9 \%$ discontinued FC because of unsatisfactory effectiveness. Iron-related parameters gradually increased after the initiation of FC treatment but stabilized after week 36. Effectiveness was analyzed in 2367 patients. Serum phosphorus immediately decreased, and the effect persisted for 104 weeks.

Conclusion In this 104 week surveillance study, no new safety concerns were noted. The safety profile was not obviously different from those in pre-approval clinical trials and the 52 week interim report of this surveillance study. The serum ferritin level of most patients was below the upper limit of the target range, and iron overload risk was not evident. Long-term FC treatment effectively controlled serum phosphorus.
\end{abstract}

Keywords Ferric citrate $\cdot$ Chronic kidney disease $\cdot$ Hyperphosphatemia $\cdot$ Dialysis $\cdot$ Non-dialysis-dependent $\cdot$ Long-term safety

Keitaro Yokoyama

keitaro@jikei.ac.jp

1 Department of Health Science, The Graduate School, The Jikei University School of Medicine, 3-25-8

Nishi-Shinbashi, Minato-ku, Tokyo 105-8461, Japan

2 Pharmaceutical Division, Japan Tobacco Inc., 3-4-1 Nihonbashi-Honcho, Chuo-ku, Tokyo 103-0023, Japan

3 Medical Affairs Department, Torii Pharmaceutical Co., Ltd, 3-4-1 Nihonbashi-Honcho, Chuo-ku, Tokyo 103-0023, Japan

4 Pharmacovigilance Department, Torii Pharmaceutical Co., Ltd, 3-4-1 Nihonbashi-Honcho, Chuo-ku, Tokyo 103-0023, Japan

5 Harumi Triton Clinic of The Jikei University Hospital Harumi Island Triton Square Office Tower, W3 Floor 1-8-8 Harumi, Chuo-ku, Tokyo 104-0053, Japan

\section{Introduction}

In patients with chronic kidney disease (CKD), declining kidney function results in CKD-mineral and bone disorder (CKD-MBD), which includes hyperphosphatemia, hypercalcemia, hyperparathyroidism, and impaired bone metabolism. These disorders lead to cardiovascular calcification and bone fractures, resulting in higher morbidity and mortality in CKD patients than in healthy adults $[1,2]$, therefore, effective management of CKD-MBD is important.

In CKD patients, a high serum phosphate level is associated with CKD progression [3, 4], cardiovascular calcification [5], and all-cause mortality [6]. The Japanese CKD-MBD guidelines recommend the maintenance of the serum phosphorus $(P)$ level within the range of 
3.5-6.0 mg/dL in CKD patients undergoing hemodialysis and peritoneal dialysis [7]. Several phosphate binders are currently available in Japan, including calcium carbonate, sevelamer hydrochloride, bixalomer, lanthanum carbonate, sucroferric oxyhydroxide, and ferric citrate hydrate (FC) (Riona $^{\circledR}$; Torii Pharmaceutical Co., Ltd., Tokyo, Japan). FC is an oral iron-based phosphate binder that effectively controls the serum $P$ concentration in patients undergoing hemodialysis [8] or peritoneal dialysis [9] and in non-dialysis-dependent CKD patients [10]. In Japan, FC has been approved to treat hyperphosphatemia in patients undergoing dialysis and in non-dialysis-dependent patients since 2014. In the United States and Taiwan, ferric citrate (Auryxia ${ }^{\circledR}$; Akebia Therapeutics, Inc., Cambridge, MA, USA and Panion \& BF Biotech Inc., Taipei, Taiwan) has been approved to treat hyperphosphatemia in patients undergoing dialysis. Ferric citrate has also been shown to increase the hemoglobin level in patients with iron-deficiency anemia without CKD [11], with CKD undergoing hemodialysis [12], and with non-dialysis-dependent CKD [13]. In Japan, FC was approved to treat iron-deficiency anemia in March 2021, and ferric citrate has also been approved to treat iron-deficiency anemia in patients with non-dialysis-dependent CKD in the United States. With regard to the effect of FC on increasing hemoglobin, iron overload may be a risk factor for long-term use of FC in patients with CKD, which requires long-term safety monitoring of the serum hemoglobin and ferritin levels.

We herein report the final analysis results from a postmarketing surveillance study of FC in CKD patients with hyperphosphatemia who were undergoing either hemodialysis or peritoneal dialysis or were non-dialysis-dependent in a real-world clinical setting in Japan. The purpose of this surveillance study was to confirm the safety, especially ironrelated parameters, and effectiveness of FC in a large number of participants undergoing long-term treatment (up to 2 years) in real-world practice.

\section{Materials and methods}

\section{Surveillance design}

This prospective, multicenter, observational post-marketing surveillance study was conducted in Japan. Patients were centrally registered from January 30, 2015, and the survey was terminated on April 30, 2020. The observation period was a maximum of 2 years after treatment initiation. Case report forms were collected for four periods: from treatment initiation to $<3$ months, from $\geq 3$ to $<6$ months, from $\geq 6$ to $<12$ months, and at $\geq 12$ months (up to a maximum of 2 years).

\section{Patients}

CKD patients who were undergoing hemodialysis and/or peritoneal dialysis or were non-dialysis-dependent were eligible for this surveillance study. Patients were registered within 14 days from the initiation of FC treatment and prospectively followed up for a maximum of 2 years. Those who did not return after the first visit and those who were not registered within 14 days after treatment initiation were excluded from the analysis. All other patients were analyzed for safety (safety analysis set). Among the safety analysis set, patients in whom effectiveness could not be evaluated and those who were found not to have met the inclusion criteria were excluded; the remaining patients were analyzed for effectiveness (effectiveness analysis set).

\section{FC treatment}

FC (250 mg tablets containing approximately $60 \mathrm{mg}$ of elemental ferric iron) was to be taken orally three times per day immediately after a meal at a starting dose of $500 \mathrm{mg}$ (1500 $\mathrm{mg} /$ day) as recommended in the Japanese package insert. The dose was adjusted according to the serum $P$ concentration or clinical status. The maximum dosage allowed was $6000 \mathrm{mg} /$ day. Concomitant medications, such as other phosphate binders or iron preparations, were allowed.

\section{Safety evaluation}

Safety was analyzed in the safety analysis set, and the patients were divided into four groups according to the dialysis methods and status at registration: hemodialysis (HD) group, peritoneal dialysis (PD) group, non-dialysisdependent (ND) group, and other treatment (OT) group (i.e., combination of hemodialysis and peritoneal dialysis).

All adverse drug reactions (ADRs) were recorded for each group. Serious ADRs were defined as any ADRs that may potentially cause disabilities, hospitalization, or death. All ADRs were categorized using the preferred terms defined in MedDRA version 23.0. In this report, the frequency of hyperferritinemia was coded as a serum ferritin increase because there was no predetermined criterion to distinguish between hyperferritinemia and a serum ferritin increase. The frequencies of polycythemia, red blood cell count increase, and hematocrit increase were coded as a hemoglobin increase.

The levels of iron- and erythrocyte-related parameters, including serum ferritin, transferrin saturation (TSAT), and hemoglobin, were measured as parameters of special interest at each site using its routine measurement methods at the initiation of FC treatment; at 4, 12, 16, 24, 28, 36, 52, 
76, and 104 weeks after the initiation of FC treatment; and at discontinuation of FC treatment. The results were summarized for the HD, PD, and ND groups. The OT group was excluded from this analysis because of its small size.

\section{Effectiveness evaluation}

The serum $P$, corrected calcium (cCa), and intact parathyroid hormone (iPTH) levels were monitored to evaluate treatment effectiveness in the effectiveness analysis set. These parameters were measured at each site using its routine measurement methods at the initiation of FC treatment; at $4,12,16,24,28,36,52,76$, and 104 weeks after the initiation of FC treatment; and at treatment discontinuation. The cCa was calculated using absolute values of serum calcium $[\mathrm{mg} / \mathrm{dL}]$ and serum albumin $[\mathrm{g} / \mathrm{dL}]$ as 1$)$ when serum albumin was $<4.0 \mathrm{~g} / \mathrm{dL}, \mathrm{cCa}[\mathrm{mg} / \mathrm{dL}]=$ (absolute value of serum calcium $)+[4-($ serum albumin $)]$; and 2$)$ when serum albumin was $\geq 4.0 \mathrm{~g} / \mathrm{dL}, \mathrm{cCa}[\mathrm{mg} / \mathrm{dL}]=$ absolute value of serum calcium. The values were summarized in the HD, PD, and ND groups. The OT group was excluded from this analysis because of its small size. Furthermore, nine-section charts were made based on the levels of serum $P$ and cCa in $\mathrm{HD}$ and PD patients to evaluate treatment effectiveness. This chart was not used for ND patients, because it is only recommended for patients receiving dialysis for clinical decisionmaking in the treatment of hypercalcemia and hyperphosphatemia in Japan [7].

\section{Statistics}

Demographics and ADR frequency among the patients in the safety analysis set were descriptively summarized for each treatment group.

Based on the data from all Japanese pre-approval clinical studies, we planned to enroll 1000 patients in the HD group, 100 in the PD group, and 500 in the ND group. This would allow the identification of an evaluable number of ADRs (i.e., serum ferritin increase and hemoglobin increase) in each group during the 104 week follow-up period.

\section{Results}

\section{Patient demographics and treatments}

The patients' demographics and treatments were summarized in the safety analysis set of 2723 patients, including 1567 in the HD, 209 in the PD, 924 in the ND, and 23 in the OT groups (Table 1). During the surveillance period, 2811 patients from 573 facilities were registered, and 2735 case report forms from 558 facilities were collected (Fig. 1). The mean age \pm standard deviation $(\mathrm{SD})$ was $65.6 \pm 13.0$ years and the proportion of men was $60.34 \%$ in the overall population, and there was no notable difference among patients in the HD, PD, ND, and OT groups. The most frequent primary disease in the overall population was diabetic kidney disease (41.0\%), followed by chronic glomerulonephritis, including IgA nephropathy (23.4\%) and nephrosclerosis (18.0\%).

Overall, 2710/2723 patients (99.52\%) received concomitant medications. About half of the overall population (1422/2723 patients; 52.22\%) received hyperphosphatemia therapy other than FC (Table 1). The most commonly used hyperphosphatemia therapy was precipitated calcium carbonate $(971 / 2723$ patients, $35.66 \%)$, followed by lanthanum carbonate hydrate (601/2723 patients, $22.07 \%)$, and sevelamer hydrochloride (173/2723 patients, $6.35 \%)$. Gastric secretion inhibitors, such as histamine type-2 receptor antagonists, proton pump inhibitors, and medication to prevent non-steroidal anti-inflammatory drug-induced ulcers, were used in 1437/2723 patients (52.77\%). Erythropoiesisstimulating agents (ESAs) were used in 2476/2723 patients (90.93\%), and iron preparations were used in 510/2723 patients $(18.73 \%)$.

All 2723 patients received FC. In total, 1692/2723 patients $(62.1 \%)$ discontinued the treatment (Table 2). The reason for discontinuation was adverse events in 558/2723 patients $(20.5 \%)$ and unsatisfactory effectiveness in $105 / 2723$ patients $(3.9 \%)$. The mean treatment period \pm SD of FC was $419.3 \pm 280.1$ days in the overall population, $465.8 \pm 281.0$ days in the HD, $402.2 \pm 272.5$ days in the $\mathrm{PD}, 340.3 \pm 262.8$ days in the ND, and $587.9 \pm 188.6$ days in the OT groups (Table 1). The mean daily dose \pm SD of FC was $995.1 \pm 496.9 \mathrm{mg}$ in the overall population $(1079.6 \pm 511.2 \mathrm{mg}$ in the HD, $972.0 \pm 499.4 \mathrm{mg}$ in the PD, $853.6 \pm 436.0 \mathrm{mg}$ in the ND, and $1126.3 \pm 485.1 \mathrm{mg}$ in the OT groups).

\section{Safety}

The frequently observed ADRs in each treatment group in the safety analysis set are summarized in Table 3. In total, 445 ADRs were reported in $323 / 1567$ patients $(20.61 \%)$ in the HD, 67 events in 51/209 patients $(24.40 \%)$ in the PD, 188 events in $151 / 924$ patients $(16.34 \%)$ in the ND, and 8 events in $7 / 23$ patients $(30.43 \%)$ in the OT groups. An increased serum ferritin level was the most commonly reported ADR (4.52\%). Gastrointestinal ADRs observed in more than $1 \%$ of patients in any group were diarrhea [56/1567 patients $(3.57 \%)$ in the HD, $13 / 209$ patients $(6.22 \%)$ in the $\mathrm{PD}, 42 / 924$ patients $(4.55 \%)$ in the ND, and $1 / 23$ patients $(4.35 \%)$ in the OT groups], constipation [28/1567 patients (1.79\%) in the HD, 3/209 patients $(1.44 \%)$ in the PD, $14 / 924$ patients $(1.52 \%)$ in the ND, and $1 / 23$ patients $(4.35 \%)$ in the OT groups], and nausea 
Table 1 Patient demographics and treatments in each group (safety analysis set)

\begin{tabular}{|c|c|c|c|c|c|}
\hline & $\begin{array}{l}\text { Total } \\
n(\%)\end{array}$ & $\begin{array}{l}\mathrm{HD} \\
n(\%)\end{array}$ & $\begin{array}{l}\mathrm{PD} \\
n(\%)\end{array}$ & $\begin{array}{l}\text { ND } \\
n(\%)\end{array}$ & $\begin{array}{l}\text { OT } \\
n(\%)\end{array}$ \\
\hline Safety analysis set & $2723(100.00)$ & $1567(100.00)$ & $209(100.00)$ & $924(100.00)$ & $23(100.00)$ \\
\hline \multicolumn{6}{|l|}{ Sex } \\
\hline Male & $1643(60.34)$ & $992(63.31)$ & $142(67.94)$ & $493(53.35)$ & $16(69.57)$ \\
\hline Female & $1080(39.66)$ & $575(36.69)$ & $67(32.06)$ & $431(46.65)$ & $7(30.43)$ \\
\hline \multicolumn{6}{|l|}{ Age [years] } \\
\hline$<20$ & $0(0.00)$ & $0(0.00)$ & $0(0.00)$ & $0(0.00)$ & $0(0.00)$ \\
\hline$\geq 20$ to $<30$ & $14(0.51)$ & $7(0.45)$ & $0(0.00)$ & $7(0.76)$ & $0(0.00)$ \\
\hline$\geq 30$ to $<40$ & $72(2.64)$ & $39(2.49)$ & $8(3.83)$ & $24(2.60)$ & $1(4.35)$ \\
\hline$\geq 40$ to $<50$ & $258(9.47)$ & $145(9.25)$ & $22(10.53)$ & $87(9.42)$ & $4(17.39)$ \\
\hline$\geq 50$ to $<60$ & $466(17.11)$ & $255(16.27)$ & $46(22.01)$ & $159(17.21)$ & $6(26.09)$ \\
\hline$\geq 60$ to $<70$ & $817(30.00)$ & $504(32.16)$ & $65(31.10)$ & $243(26.30)$ & $5(21.74)$ \\
\hline$\geq 70$ to $<80$ & $693(25.45)$ & $408(26.04)$ & $46(22.01)$ & $232(25.11)$ & $7(30.43)$ \\
\hline$\geq 80$ & $403(14.80)$ & 209 (13.34) & $22(10.53)$ & $172(18.61)$ & $0(0.00)$ \\
\hline Mean \pm standard deviation & $65.6 \pm 13.0$ & $65.6 \pm 12.7$ & $63.4 \pm 12.7$ & $66.2 \pm 13.6$ & $61.1 \pm 11.5$ \\
\hline \multicolumn{6}{|l|}{ Study visit } \\
\hline Hospitalization & $126(4.63)$ & $39(2.49)$ & $20(9.57)$ & $65(7.03)$ & $2(8.70)$ \\
\hline Ambulatory & $2597(95.37)$ & $1528(97.51)$ & $189(90.43)$ & $859(92.97)$ & $21(91.30)$ \\
\hline \multicolumn{6}{|l|}{ Primary disease underlying $\mathrm{CKD}^{\mathrm{a}}$} \\
\hline Diabetic kidney disease & $1116(40.98)$ & $650(41.48)$ & $80(38.28)$ & $377(40.80)$ & $9(39.13)$ \\
\hline $\begin{array}{l}\text { Chronic glomerulonephritis, includ- } \\
\text { ing IgA nephropathy }\end{array}$ & $638(23.43)$ & $393(25.08)$ & $59(28.23)$ & $178(19.26)$ & $8(34.78)$ \\
\hline Nephrosclerosis & $490(17.99)$ & $243(15.51)$ & $48(22.97)$ & $197(21.32)$ & $2(8.70)$ \\
\hline Polycystic kidney disease & $125(4.59)$ & $64(4.08)$ & $6(2.87)$ & $55(5.95)$ & $0(0.00)$ \\
\hline Others & $179(6.57)$ & $100(6.38)$ & $6(2.87)$ & $70(7.58)$ & $3(13.04)$ \\
\hline Unknown & $284(10.43)$ & $168(10.72)$ & $15(7.18)$ & $99(10.71)$ & $2(8.70)$ \\
\hline \multicolumn{6}{|l|}{ Dialysis vintage [years] } \\
\hline$<0.5$ & $212(7.79)$ & $167(10.66)$ & $45(21.53)$ & $0(0.00)$ & $0(0.00)$ \\
\hline$\geq 0.5$ to $<1$ & $227(8.34)$ & $192(12.25)$ & $32(15.31)$ & $0(0.00)$ & $3(13.04)$ \\
\hline$\geq 1$ to $<3$ & $379(13.92)$ & $306(19.53)$ & $67(32.06)$ & $0(0.00)$ & $6(26.09)$ \\
\hline$\geq 3$ to $<5$ & $260(9.55)$ & $214(13.66)$ & $40(19.14)$ & $0(0.00)$ & $6(26.09)$ \\
\hline$\geq 5$ to $<10$ & $385(14.14)$ & $356(22.72)$ & $24(11.48)$ & $0(0.00)$ & $5(21.74)$ \\
\hline$\geq 10$ to $<20$ & $246(9.03)$ & $242(15.44)$ & $1(0.48)$ & $0(0.00)$ & $3(13.04)$ \\
\hline$\geq 20$ & $89(3.27)$ & $89(5.68)$ & $0(0.00)$ & $0(0.00)$ & $0(0.00)$ \\
\hline Unknown & $925(33.97)$ & $1(0.06)$ & $0(0.00)$ & $924(100.00)$ & $0(0.00)$ \\
\hline \multicolumn{6}{|l|}{ Complications } \\
\hline Absent & $96(3.53)$ & $76(4.85)$ & $3(1.44)$ & $16(1.73)$ & $1(4.35)$ \\
\hline Present $^{\mathrm{a}}$ & $2623(96.33)$ & $1488(94.96)$ & $206(98.56)$ & $908(98.27)$ & $21(91.30)$ \\
\hline Gastrointestinal disorders & $1214(44.58)$ & $831(53.03)$ & $93(44.50)$ & $281(30.41)$ & $9(39.13)$ \\
\hline Cardiovascular disorders & $2363(86.78)$ & $1299(82.90)$ & $192(91.87)$ & $852(92.21)$ & $20(86.96)$ \\
\hline Liver disorders & $174(6.39)$ & $101(6.45)$ & $14(6.70)$ & $59(6.39)$ & $0(0.00)$ \\
\hline Metabolic disorders & $2132(78.30)$ & $1110(70.84)$ & $179(85.65)$ & $825(89.29)$ & $18(78.26)$ \\
\hline Others & $2278(83.66)$ & $1336(85.26)$ & $182(87.08)$ & $740(80.09)$ & $20(86.96)$ \\
\hline Unknown & $4(0.15)$ & $3(0.19)$ & $0(0.00)$ & $0(0.00)$ & $1(4.35)$ \\
\hline \multicolumn{6}{|l|}{ Any concomitant drugs } \\
\hline No & $13(0.48)$ & $4(0.26)$ & $0(0.00)$ & $9(0.97)$ & $0(0.00)$ \\
\hline Yes & $2710(99.52)$ & $1563(99.74)$ & $209(100.00)$ & $915(99.03)$ & $23(100.00)$ \\
\hline \multicolumn{6}{|l|}{ Phosphate binders ${ }^{\mathrm{a}}$} \\
\hline No & $1301(47.78)$ & $537(34.27)$ & $82(39.23)$ & $679(73.48)$ & $3(13.04)$ \\
\hline Yes & $1422(52.22)$ & $1030(65.73)$ & $127(60.77)$ & $245(26.52)$ & $20(86.96)$ \\
\hline
\end{tabular}


Table 1 (continued)

\begin{tabular}{|c|c|c|c|c|c|}
\hline & $\begin{array}{l}\text { Total } \\
n(\%)\end{array}$ & $\begin{array}{l}\mathrm{HD} \\
n(\%)\end{array}$ & $\begin{array}{l}\mathrm{PD} \\
n(\%)\end{array}$ & $\begin{array}{l}\mathrm{ND} \\
n(\%)\end{array}$ & $\begin{array}{l}\text { OT } \\
n(\%)\end{array}$ \\
\hline Precipitated calcium carbonate & $971(35.66)$ & $689(43.97)$ & 75 (35.89) & $195(21.10)$ & $12(52.17)$ \\
\hline Sevelamer hydrochloride & $173(6.35)$ & $157(10.02)$ & $9(4.31)$ & $3(0.32)$ & $4(17.39)$ \\
\hline Bixalomer & $117(4.30)$ & $88(5.62)$ & $17(8.13)$ & $11(1.19)$ & $1(4.35)$ \\
\hline Lanthanum carbonate hydrate & $601(22.07)$ & $474(30.25)$ & $57(27.27)$ & $61(6.60)$ & $9(39.13)$ \\
\hline Sucroferric oxyhydroxide & $34(1.25)$ & $28(1.79)$ & $2(0.96)$ & $4(0.43)$ & $0(0.00)$ \\
\hline $\begin{array}{l}\text { Dried aluminum hydroxide gel, mag- } \\
\text { nesium hydroxide }\end{array}$ & $1(0.04)$ & $1(0.06)$ & $0(0.00)$ & $0(0.00)$ & $0(0.00)$ \\
\hline \multicolumn{6}{|l|}{ Secondary hyperparathyroidism drugs } \\
\hline No & $838(30.77)$ & $297(18.95)$ & $41(19.62)$ & $497(53.79)$ & $3(13.04)$ \\
\hline Yes & $1885(69.23)$ & $1270(81.05)$ & $168(80.38)$ & $427(46.21)$ & $20(86.96)$ \\
\hline \multicolumn{6}{|l|}{ Erythropoiesis-stimulating agents } \\
\hline No & $247(9.07)$ & $117(7.47)$ & $4(1.91)$ & $125(13.53)$ & $1(4.35)$ \\
\hline Yes & $2476(90.93)$ & $1450(92.53)$ & $205(98.09)$ & 799 (86.47) & $22(95.65)$ \\
\hline \multicolumn{6}{|l|}{ Gastric secretion inhibitors } \\
\hline No & $1286(47.23)$ & $613(39.12)$ & $104(49.76)$ & $557(60.28)$ & $12(52.17)$ \\
\hline Yes & $1437(52.77)$ & $954(60.88)$ & $105(50.24)$ & 367 (39.72) & $11(47.83)$ \\
\hline \multicolumn{6}{|l|}{ Iron preparations } \\
\hline No & $2213(81.27)$ & $1158(73.90)$ & $191(91.39)$ & $844(91.34)$ & $20(86.96)$ \\
\hline Yes & $510(18.73)$ & 409 (26.10) & $18(8.61)$ & $80(8.66)$ & $3(13.04)$ \\
\hline \multicolumn{6}{|l|}{ Others } \\
\hline No & $239(8.78)$ & $139(8.87)$ & $28(13.40)$ & $69(7.47)$ & $3(13.04)$ \\
\hline Yes & $2484(91.22)$ & $1428(91.13)$ & $181(86.60)$ & $855(92.53)$ & $20(86.96)$ \\
\hline \multicolumn{6}{|l|}{ Average daily dose [mg] } \\
\hline$<500$ & $174(6.39)$ & $68(4.34)$ & $23(11.00)$ & $81(8.77)$ & $2(8.70)$ \\
\hline$\geq 500$ to $<1000$ & $1504(55.23)$ & $784(50.03)$ & $105(50.24)$ & $607(65.69)$ & $8(34.78)$ \\
\hline$\geq 1000$ to $<1500$ & $320(11.75)$ & $205(13.08)$ & $28(13.40)$ & $83(8.98)$ & $4(17.39)$ \\
\hline$\geq 1500$ to $<2000$ & $628(23.06)$ & $430(27.44)$ & $46(22.01)$ & $144(15.58)$ & $8(34.78)$ \\
\hline$\geq 2000$ to $<2500$ & $72(2.64)$ & $60(3.83)$ & $5(2.39)$ & $6(0.65)$ & $1(4.35)$ \\
\hline$\geq 2500$ to $<3000$ & $17(0.62)$ & $15(0.96)$ & $1(0.48)$ & $1(0.11)$ & $0(0.00)$ \\
\hline$\geq 3000$ & $8(0.29)$ & $5(0.32)$ & $1(0.48)$ & $2(0.22)$ & $0(0.00)$ \\
\hline Mean \pm standard deviation & $995.1 \pm 496.9$ & $1079.6 \pm 511.2$ & $972.0 \pm 499.4$ & $853.6 \pm 436.0$ & $1126.3 \pm 485.1$ \\
\hline \multicolumn{6}{|l|}{ Mean treatment period [days] } \\
\hline Mean \pm standard deviation & $419.3 \pm 280.1$ & $465.8 \pm 281.0$ & $402.2 \pm 272.5$ & $340.3 \pm 262.8$ & $587.9 \pm 188.6$ \\
\hline
\end{tabular}

$H D$ hemodialysis, $P D$ peritoneal dialysis, $N D$ non-dialysis-dependent, $O T$ other treatment, $C K D$ chronic kidney disease, $I g A$ immunoglobulin A

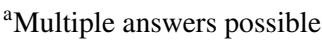

[19/1567 patients $(1.21 \%)$ in the HD, $1 / 209$ patients $(0.48 \%)$ in the PD, $10 / 924$ patients $(1.08 \%)$ in the ND, and $0 / 23$ patients in the OT groups].

In the overall population, 73 serious ADRs were observed in $60 / 2723$ patients $(2.20 \%)$, including 37 events in $30 / 1567$ patients $(1.91 \%)$ in the HD, 6 events in 5/209 patients $(2.39 \%)$ in the PD, 30 events in $25 / 924$ patients $(2.71 \%)$ in the ND, and 0 events in $0 / 23$ patients in the OT groups (Table 4). Among those, 17 of all 2723 patients $(0.62 \%)$ died.

\section{Safety: parameters of special interest}

A serum ferritin increase, including hyperferritinemia, was observed in 60/1567 patients in the HD (3.83\%), 19/209 patients $(9.09 \%)$ in the $\mathrm{PD}, 40 / 924$ patients $(4.33 \%)$ in the ND, and $4 / 23$ patients (17.39\%) in the OT groups (Table 3 ). At treatment initiation, the median (first quartile, third quartile) ferritin levels were $44.50(21.40,88.10) \mathrm{ng} / \mathrm{mL}$ in the HD, $95.15(51.00,167.80) \mathrm{ng} / \mathrm{mL}$ in the PD, and $82.65(43.00,147.20) \mathrm{ng} / \mathrm{mL}$ in the ND groups (Fig. 2a). The levels showed a stable increasing trend, and at week 36 
Fig. 1 Patient flow

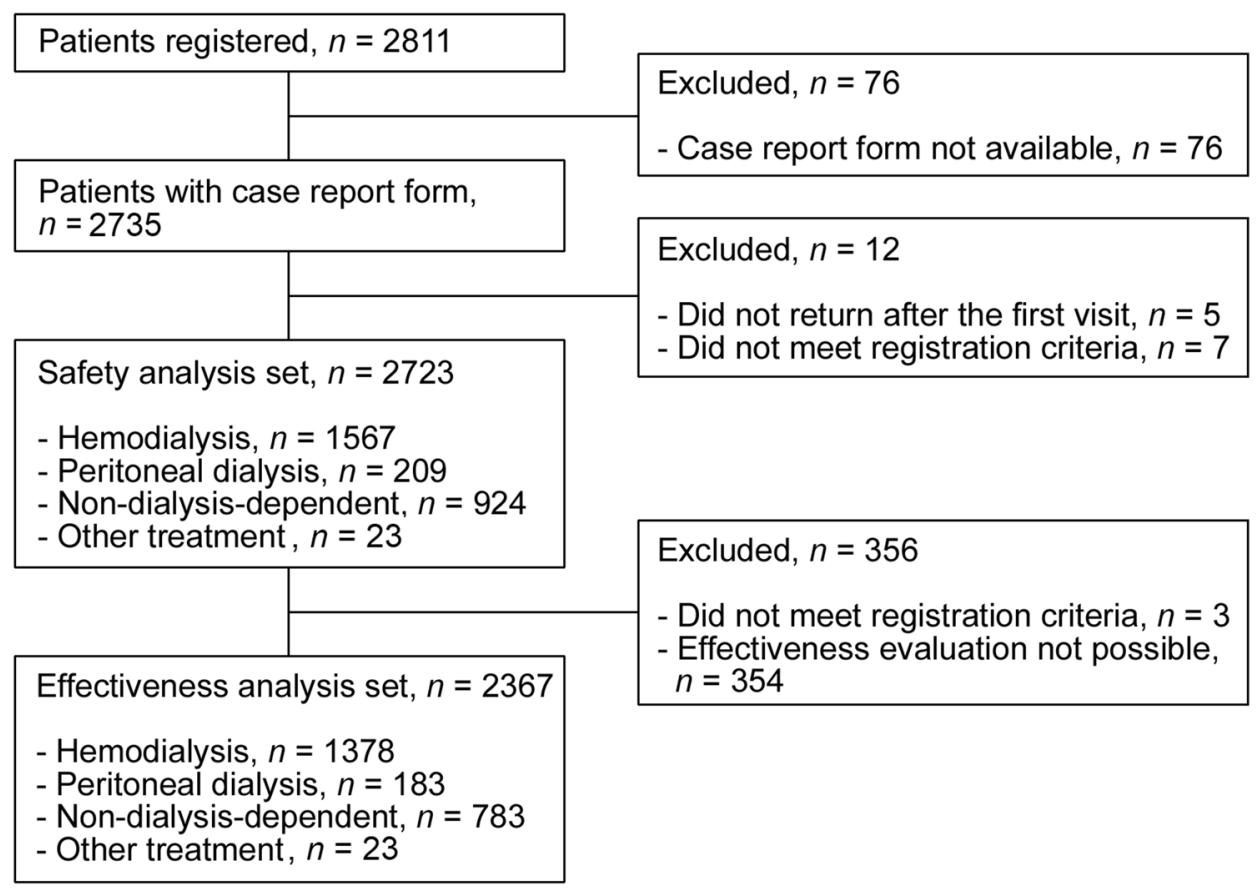

Table 2 Summary of discontinuation (safety analysis set)

\begin{tabular}{lrrrrrr}
\hline \multicolumn{7}{l}{ Observation period (months) } \\
\cline { 2 - 7 } & At initiation & $<3$ & $\geq 3$ to $<6$ & $\geq 6$ to $<12$ & $\geq 12$ & Total \\
\hline Safety analysis set, $n$ & 2723 & 2723 & 2348 & 1916 & 1502 & 2723 \\
HD & 1567 & 1567 & 1376 & 1168 & 986 & 1567 \\
PD & 209 & 209 & 182 & 150 & 110 & 209 \\
ND & 924 & 924 & 767 & 576 & 386 & 924 \\
OT & 23 & 23 & 23 & 22 & 20 & 23 \\
Treatment discontinuation, $n$ & 0 & 375 & 432 & 414 & 471 & 1692 \\
Adverse events & 0 & 185 & 114 & 117 & 142 & 558 \\
Effectiveness not satisfactory & 0 & 15 & 28 & 30 & 32 & 105 \\
Hospital switched; treatment & 0 & 81 & 101 & 102 & 115 & 399 \\
visits stopped & & & & & 74 & 241 \\
Follow-up not possible & 0 & 0 & 99 & 68 & 108 & 389 \\
Other reasons & 0 & 94 & 90 & 97 & & \\
\hline
\end{tabular}

$H D$ hemodialysis, $P D$ peritoneal dialysis, $N D$ non-dialysis-dependent, $O T$ other treatment

they were $120.70(72.00,198.30) \mathrm{ng} / \mathrm{mL}$ in the HD, 222.10 $(127.80,312.80) \mathrm{ng} / \mathrm{mL}$ in the PD, and 162.00 (93.00, $254.00) \mathrm{ng} / \mathrm{mL}$ in the ND groups. The levels subsequently showed the tendency to stabilize: the ferritin levels at week 104 were $124.00(71.00,223.00) \mathrm{ng} / \mathrm{mL}$ in the HD, 262.10 (209.55, 405.60) $\mathrm{ng} / \mathrm{mL}$ in the PD, and 186.00 (84.90, $281.50) \mathrm{ng} / \mathrm{mL}$ in the ND groups. The time-course changes in the TSAT levels were similar to those of the serum ferritin levels. At FC treatment initiation, the mean \pm SD TSAT was $21.97 \pm 12.09 \%$ in the HD, $30.30 \pm 13.77 \%$ in the PD, and $27.58 \pm 12.52 \%$ in the ND groups (Fig. 2b). The levels showed a gradually increasing trend, and at week 36 they were $31.59 \pm 11.83 \%$ in the HD, $39.88 \pm 12.43 \%$ in the PD, and $36.11 \pm 14.75 \%$ in the ND groups. They subsequently showed the tendency to stabilize. The TSAT levels at week 104 were $31.41 \pm 13.35 \%$ in the HD, $37.24 \pm 17.78 \%$ in the PD, and $33.61 \pm 13.85 \%$ in the ND groups. The mean hemoglobin level showed an increasing trend in all treatment groups. The mean \pm SD hemoglobin levels at treatment initiation were $10.67 \pm 1.22 \mathrm{~g} / \mathrm{dL}$ in the HD, $10.54 \pm 1.26 \mathrm{~g} /$ $\mathrm{dL}$ in the $\mathrm{PD}$, and $10.37 \pm 1.32 \mathrm{~g} / \mathrm{dL}$ in the ND groups (Fig. 2c). The levels at week 104 were $11.21 \pm 1.23 \mathrm{~g} / \mathrm{dL}$ in the HD, $11.21 \pm 1.26 \mathrm{~g} / \mathrm{dL}$ in the PD, and $11.41 \pm 1.47 \mathrm{~g} /$ $\mathrm{dL}$ in the ND groups. A serious serum ferritin increase was 
Table 3 Adverse drug reactions observed in five or more patients in safety analysis set of this study (safety analysis set)

\begin{tabular}{|c|c|c|c|c|c|c|}
\hline & Pre-approval total ${ }^{\mathrm{a}}$ & Post-mark & surveillan & & & \\
\hline & & HD & PD & ND & OT & Total \\
\hline Safety analysis set, $n$ & 801 & 1567 & 209 & 924 & 23 & 2723 \\
\hline Patients with any ADRs, $n$ & 204 & 323 & 51 & 151 & 7 & 532 \\
\hline ADRs, $n$ & - & 445 & 67 & 188 & 8 & 708 \\
\hline Proportion of patients with any ADRs, $\%$ & 25.47 & 20.61 & 24.40 & 16.34 & 30.43 & 19.54 \\
\hline ADRs, $n(\%)$ & & & & & & \\
\hline Serum ferritin increased ${ }^{\mathrm{b}}$ & $22(2.75)$ & $60(3.83)$ & $19(9.09)$ & $40(4.33)$ & $4(17.39)$ & $123(4.52)$ \\
\hline Diarrhea & $55(6.87)$ & $56(3.57)$ & $13(6.22)$ & $42(4.55)$ & $1(4.35)$ & $112(4.11)$ \\
\hline Hemoglobin increased $^{c}$ & $20(2.50)$ & $50(3.19)$ & $0(0.00)$ & $1(0.11)$ & $0(0.00)$ & $51(1.87)$ \\
\hline Constipation & $26(3.25)$ & $28(1.79)$ & $3(1.44)$ & $14(1.52)$ & $1(4.35)$ & $46(1.69)$ \\
\hline Nausea & $7(0.87)$ & $19(1.21)$ & $1(0.48)$ & $10(1.08)$ & $0(0.00)$ & $30(1.10)$ \\
\hline Hypertension & $4(0.50)$ & $12(0.77)$ & $2(0.96)$ & $3(0.32)$ & $0(0.00)$ & $17(0.62)$ \\
\hline Abdominal discomfort & $20(2.50)$ & $12(0.77)$ & $0(0.00)$ & $3(0.32)$ & $0(0.00)$ & $15(0.55)$ \\
\hline Feces discolored & $1(0.12)$ & $12(0.77)$ & $0(0.00)$ & $0(0.00)$ & $0(0.00)$ & $12(0.44)$ \\
\hline Abdominal distension & $10(1.25)$ & $9(0.57)$ & $0(0.00)$ & $3(0.32)$ & $0(0.00)$ & $12(0.44)$ \\
\hline Vomiting & $6(0.75)$ & $7(0.45)$ & $1(0.48)$ & $0(0.00)$ & $0(0.00)$ & $8(0.29)$ \\
\hline Feces soft & $29(3.62)$ & $6(0.38)$ & $0(0.00)$ & $2(0.22)$ & $0(0.00)$ & $8(0.29)$ \\
\hline Decreased appetite & $3(0.37)$ & $5(0.32)$ & $1(0.48)$ & $4(0.43)$ & $0(0.00)$ & $10(0.37)$ \\
\hline Pruritus & $2(0.25)$ & $5(0.32)$ & $0(0.00)$ & $3(0.32)$ & $0(0.00)$ & $8(0.29)$ \\
\hline Abdominal pain & $7(0.87)$ & $4(0.26)$ & $1(0.48)$ & $2(0.22)$ & $0(0.00)$ & $7(0.26)$ \\
\hline Gastroesophageal reflux disease & $0(0.00)$ & $3(0.19)$ & $1(0.48)$ & $1(0.11)$ & $0(0.00)$ & $5(0.18)$ \\
\hline Blood iron increased & $0(0.00)$ & $2(0.13)$ & $1(0.48)$ & $2(0.22)$ & $0(0.00)$ & $5(0.18)$ \\
\hline Hepatic function abnormal & $4(0.50)$ & $1(0.06)$ & $2(0.96)$ & $3(0.32)$ & $0(0.00)$ & $6(0.22)$ \\
\hline Renal impairment & $0(0.00)$ & $0(0.00)$ & $0(0.00)$ & $5(0.54)$ & $0(0.00)$ & $5(0.18)$ \\
\hline
\end{tabular}

$A D R$ adverse drug reaction, $H D$ hemodialysis, $P D$ peritoneal dialysis, $N D$ non-dialysis-dependent, $O T$ other treatment

${ }^{a}$ Data from pre-approval clinical studies conducted in Japan

${ }^{b}$ Including the occurrence of hyperferritinemia

${ }^{\mathrm{c}}$ Including the occurrence of polycythemia, red blood cell count increased, and hematocrit increased

observed in $4 / 2723$ patients $(0.15 \%)$ overall, all of whom were in the ND group $(4 / 924,0.43 \%)$ (Table 4$)$. The physicians subjectively determined the seriousness of the serum ferritin increase because of the lack of predetermined criteria. Although iron overload is associated with an increased risk of hepatic dysfunction or infectious disease, such ADRs were not observed in these four patients with a serious serum ferritin increase. No other serious ADRs involving parameters of special interest were observed.

\section{Effectiveness}

The effectiveness analysis set comprised 2367 patients (1378 in the HD, 183 in the PD, 783 in the ND, and 23 in the OT groups). After the FC treatment initiation, the serum $P$ level showed an immediate decreasing trend in all groups (Fig. 3a). At FC treatment initiation, the mean serum $P$ level \pm SD was $6.58 \pm 1.39 \mathrm{mg} / \mathrm{dL}$ in the HD, $6.16 \pm 1.37 \mathrm{mg} / \mathrm{dL}$ in the PD, and $5.34 \pm 1.04 \mathrm{mg} / \mathrm{dL}$ in the ND groups. At week 104, the mean serum $P$ level \pm SD was $5.37 \pm 1.30 \mathrm{mg} / \mathrm{dL}$ in the HD,
$5.14 \pm 1.28 \mathrm{mg} / \mathrm{dL}$ in the PD, and $4.86 \pm 1.16 \mathrm{mg} / \mathrm{dL}$ in the ND groups. The levels of serum cCa (Fig. 3b) and iPTH (Fig. 3c) did not substantially change in any group. Figure 4 shows the nine-section charts for HD and PD patients at baseline and at week 104. The center section shows that the target ranges of both serum $P(3.5-6.0 \mathrm{mg} / \mathrm{dL})$ and serum cCa (8.4-10.0 mg/ $\mathrm{dL})$ were achieved [7]. At baseline, proportions of patients in the center section were $22.4 \%$ in the HD and $36.0 \%$ in the PD groups (Fig. 4a, c), indicating insufficient serum $P$ and cCa management. At 104 weeks after FC treatment initiation, the highest proportion of patients was in the center section (57.6\% in the $\mathrm{HD}$ and $54.8 \%$ in the PD groups) (Fig. 4b, d).

\section{Discussion}

The ferric iron from FC binds to ingested $P$ in the gastrointestinal tract and forms insoluble ferric phosphate, which promotes fecal $P$ excretion [14]. Pre-approval clinical trials for CKD patients with hyperphosphatemia showed that FC 
Table 4 Serious adverse drug reactions (safety analysis set)

\begin{tabular}{|c|c|c|c|c|c|}
\hline & HD & PD & ND & OT & Total \\
\hline Safety analysis set, $n$ & 1567 & 209 & 924 & 23 & 2723 \\
\hline Patients with any serious ADRs, $n$ & 30 & 5 & 25 & 0 & 60 \\
\hline Serious ADRs, $n$ & 37 & 6 & 30 & 0 & 73 \\
\hline Proportion of patients with any serious ADRs, $\%$ & 1.91 & 2.39 & 2.71 & 0.00 & 2.20 \\
\hline \multicolumn{6}{|l|}{$\mathrm{ADR}, n(n \text { of deaths })^{\mathrm{a}}$} \\
\hline Infections and infestations & $1(1)$ & 1 & $2(1)$ & & $4(2)$ \\
\hline Peritonitis & $1(1)$ & 1 & & & $2(1)$ \\
\hline Urinary tract infection & & & 1 & & 1 \\
\hline Renal cyst infection & & & $1(1)$ & & $1(1)$ \\
\hline $\begin{array}{l}\text { Neoplasms benign, malignant and unspecified (includ- } \\
\text { ing cysts and polyps) }\end{array}$ & $2(1)$ & & & & $2(1)$ \\
\hline Gastric cancer & 1 & & & & 1 \\
\hline Lymphoma & $1(1)$ & & & & $1(1)$ \\
\hline Blood and lymphatic system disorders & & & $2(1)$ & & $2(1)$ \\
\hline Eosinophilia & & & $2(1)$ & & $2(1)$ \\
\hline Metabolism and nutrition disorders & 3 & 1 & 1 & & 5 \\
\hline Dehydration & 1 & & & & 1 \\
\hline Hyperphosphatemia & 1 & & & & 1 \\
\hline Hypocalcemia & & & 1 & & 1 \\
\hline Hyponatremia & & 1 & & & 1 \\
\hline Decreased appetite & 1 & & & & 1 \\
\hline Nervous system disorders & $8(2)$ & & $2(1)$ & & $10(3)$ \\
\hline Cerebellar infarction & 1 & & 1 & & 2 \\
\hline Cerebral hemorrhage & $1(1)$ & & & & $1(1)$ \\
\hline Cerebral infarction & 3 & & & & 3 \\
\hline Subarachnoid hemorrhage & $1(1)$ & & $1(1)$ & & $2(2)$ \\
\hline Transient ischemic attack & 1 & & & & 1 \\
\hline Ischemic cerebral infarction & 1 & & & & 1 \\
\hline Cardiac disorders & $9(4)$ & & $3(2)$ & & $12(6)$ \\
\hline Acute myocardial infarction & $3(2)$ & & & & $3(2)$ \\
\hline Angina pectoris & $2(1)$ & & & & $2(1)$ \\
\hline Arrhythmia & & & $2(2)$ & & $2(2)$ \\
\hline Arteriosclerosis coronary artery & 1 & & & & 1 \\
\hline Cardiac failure & $1(1)$ & & & & $1(1)$ \\
\hline Cardiac failure chronic & 1 & & & & 1 \\
\hline Cardiac failure congestive & 2 & & 1 & & 3 \\
\hline Respiratory, thoracic and mediastinal disorders & $2(1)$ & & 1 & & $3(1)$ \\
\hline Pneumonia aspiration & $2(1)$ & & & & $2(1)$ \\
\hline Pulmonary edema & & & 1 & & 1 \\
\hline Gastrointestinal disorders & $3(1)$ & 2 & & & $5(1)$ \\
\hline Abdominal pain upper & & 1 & & & 1 \\
\hline Diarrhea & 1 & 1 & & & 2 \\
\hline Ileus & $1(1)$ & & & & $1(1)$ \\
\hline Pancreatitis & 1 & & & & 1 \\
\hline Vomiting & & 1 & & & 1 \\
\hline Hepatobiliary disorders & & & 1 & & 1 \\
\hline Hepatic function abnormal & & & 1 & & 1 \\
\hline Musculoskeletal and connective tissue disorders & 1 & & & & 1 \\
\hline Back pain & 1 & & & & 1 \\
\hline Renal and urinary disorders & & & $8(1)$ & & $8(1)$ \\
\hline Renal failure & & & 2 & & 2 \\
\hline
\end{tabular}


Table 4 (continued)

\begin{tabular}{|c|c|c|c|c|c|}
\hline & $\mathrm{HD}$ & PD & ND & OT & Total \\
\hline Renal impairment & & & 4 & & 4 \\
\hline Acute kidney injury & & & $1(1)$ & & $1(1)$ \\
\hline End stage renal disease & & & 1 & & 1 \\
\hline General disorders and administration site conditions & $2(1)$ & $1(1)$ & $3(1)$ & & $6(3)$ \\
\hline Chest pain & & & 1 & & 1 \\
\hline Death & $1(1)$ & $1(1)$ & $1(1)$ & & $3(3)$ \\
\hline Malaise & 1 & & & & 1 \\
\hline Edema due to renal disease & & & 1 & & 1 \\
\hline Investigations & 1 & & 6 & & 7 \\
\hline Blood creatinine increased & & & 1 & & 1 \\
\hline Glomerular filtration rate decreased & & & 1 & & 1 \\
\hline Hemoglobin decreased & 1 & & & & 1 \\
\hline Serum ferritin increased & & & 4 & & 4 \\
\hline Injury, poisoning and procedural complications & $4(1)$ & & 1 & & $5(1)$ \\
\hline Femoral neck fracture & $1(1)$ & & & & $1(1)$ \\
\hline Shunt occlusion & 2 & & 1 & & 3 \\
\hline Pelvic fracture & 1 & & & & 1 \\
\hline
\end{tabular}

$A D R$ adverse drug reaction, $H D$ hemodialysis, $P D$ peritoneal dialysis, $N D$ non-dialysis-dependent, OT other treatment

${ }^{a}$ Multiple events in a single patient are possible

is associated with gastrointestinal ADRs: Among all Japanese pre-approval clinical trials, 55/801 patients (6.87\%) had diarrhea and 26/801 patients (3.25\%) had constipation (Table 3). Neither of these ADRs was more frequent after the long-term use of FC in the present surveillance. All ADRs have been previously described in pre-approval clinical studies or the 52 week interim surveillance study. There were no obvious differences in ADR frequencies among the $\mathrm{HD}, \mathrm{PD}, \mathrm{ND}$, and OT groups. Overall, the ADR profile in this 104 week surveillance study was similar to that in preapproval clinical trials and the interim results of the current surveillance study [15].

Iron- and erythrocyte-related parameters were evaluated as parameters of special interest because $\mathrm{FC}$ is an iron-based phosphate binder; therefore, FC may induce iron deposition in organs [16] and increase the risk of diseases associated with iron overload, especially hepatic dysfunction.

The Japanese Society for Dialysis Therapy (JSDT) guidelines for renal anemia in patients with CKD recommend that the serum ferritin level should not exceed $300 \mathrm{ng} / \mathrm{mL}$ [17]. The serum ferritin level and TSAT level in the present surveillance study showed a gradually increasing trend after treatment initiation, and after week 36 they stayed at levels similar to those in the interim surveillance study [15]. The PD group showed the highest serum ferritin level, which was in line with previously reported clinical studies [8-10]. In these PD patients, median ferritin levels did not exceed $300 \mathrm{ng} / \mathrm{mL}(262.1 \mathrm{ng} / \mathrm{mL})$ and the hemoglobin level was well maintained within the target range recommended in the JSDT guidelines [17]. The importance of treating anemia and iron deficiency in CKD patients has recently been receiving increasing attention, as several studies have demonstrated that these conditions are associated with an increased risk of hospitalizations, cardiovascular events, or all-cause mortality $[18,19]$. FC is expected to contribute to the treatment of anemia and iron deficiency in CKD patients, but caution regarding iron overload is required, especially in PD patients. Therefore, continuous monitoring is warranted to prevent iron overload and excessive hematopoiesis in CKD patients treated with FC, and adjusting the dose of FC should be considered accordingly. It may be possible to prevent iron overload by adjusting the dose of concomitant medications, such as ESAs or iron preparations. In this study, the data were not available to evaluate if FC changed the required dose of ESAs or iron preparations. Further data accumulation is therefore necessary.

Administration of FC with other concomitant drugs effectively managed the serum $P$ level in CKD patients undergoing hemodialysis and peritoneal dialysis and in patients who were non-dialysis-dependent. Additionally, the effect was present after long-term treatment without largely affecting the levels of cCa or iPTH. In the nine-section charts, the proportions of patients within the center section were increased by FC treatment in both the HD and PD groups, and were not decreased after the long-term treatment. These results demonstrate that FC with other concomitant therapy successfully managed CKD-MBD. 
Time-course change

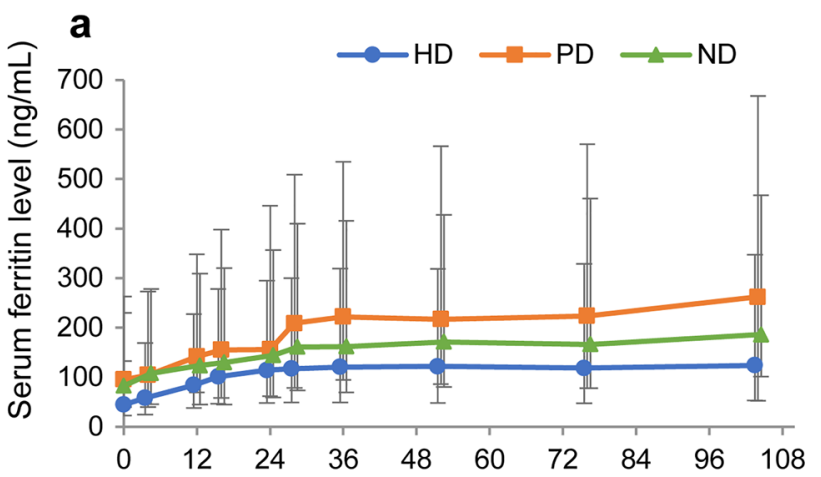

b
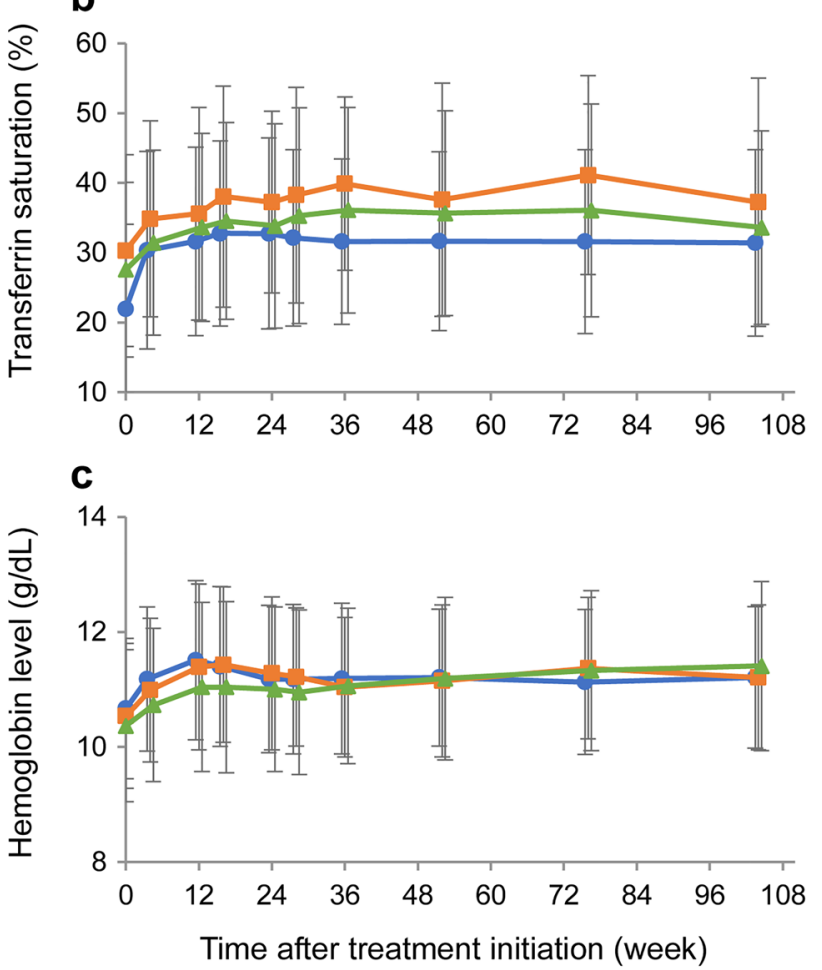

Fig. 2 Iron- and erythrocyte-related parameters of special interest (safety analysis set) Time-course changes in a serum ferritin, $\mathbf{b}$ transferrin saturation, and $\mathbf{c}$ hemoglobin. Data represent $\mathbf{a}$ median and (b, c) mean \pm standard deviation. Error bars in a are from the first to third quartiles. Blue: hemodialysis group (HD), orange: peritoneal dialysis group (PD), green: non-dialysis-dependent group (ND)

Limitations of this surveillance study include the many missing data because of the observational nature of the surveillance, the lack of a control group for comparison, and possible bias in patient selection because only patients with favorable safety and effectiveness outcomes continued FC treatment for the long term.
Time-course change
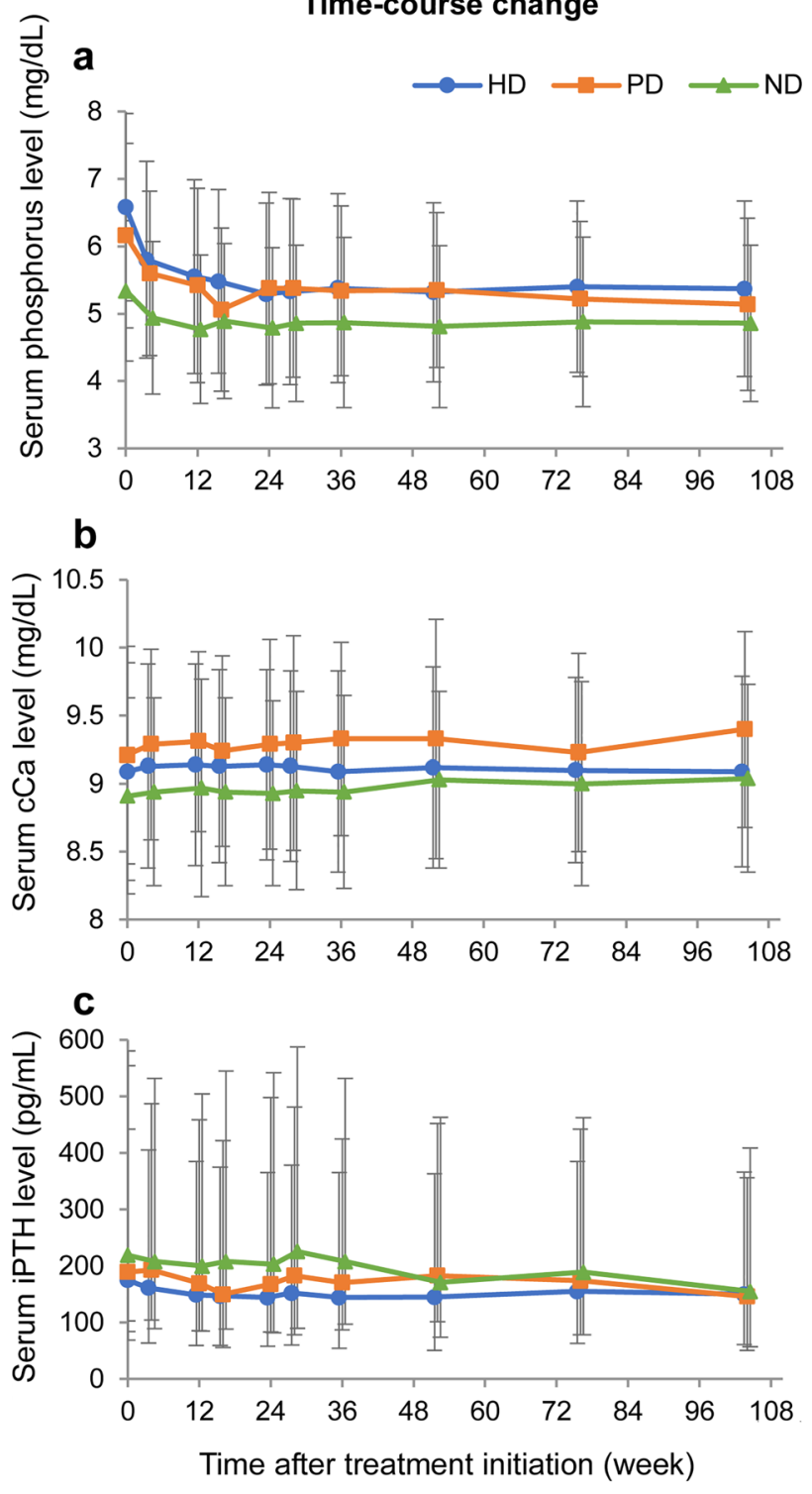

Fig. 3 Effectiveness evaluation parameters (effectiveness analysis set) Time-course changes in mean a serum phosphorus, b corrected calcium (cCa), and $\mathbf{c}$ intact parathyroid hormone (iPTH). Data represent $(\mathbf{a}, \mathbf{b})$ mean \pm standard deviation and $\mathbf{c}$ median. Error bars in $\mathbf{c}$ are from the first to third quartiles. Blue: hemodialysis group (HD), orange: peritoneal dialysis group (PD), green: non-dialysis-dependent group (ND)

\section{Conclusions}

In this prospective, multicenter, observational post-marketing surveillance study of the treatment of hyperphosphatemia with FC, no new safety issues emerged during the 104 week observation period. A risk of iron overload was not evident; the serum ferritin level of most patients remained at $<300 \mathrm{ng} / \mathrm{mL}$, the recommended upper limit of the target range in Japan. Additionally, no signs of 
Fig. 4 Nine-section charts (effectiveness analysis set) Nine-section charts for patients undergoing (a, b) hemodialysis (HD) and (c, d) peritoneal dialysis (PD) at (a, c) baseline and $(\mathbf{b}, \mathbf{d})$ week 104. Green bars designate well-managed serum phosphorus and corrected calcium $(\mathrm{cCa})$
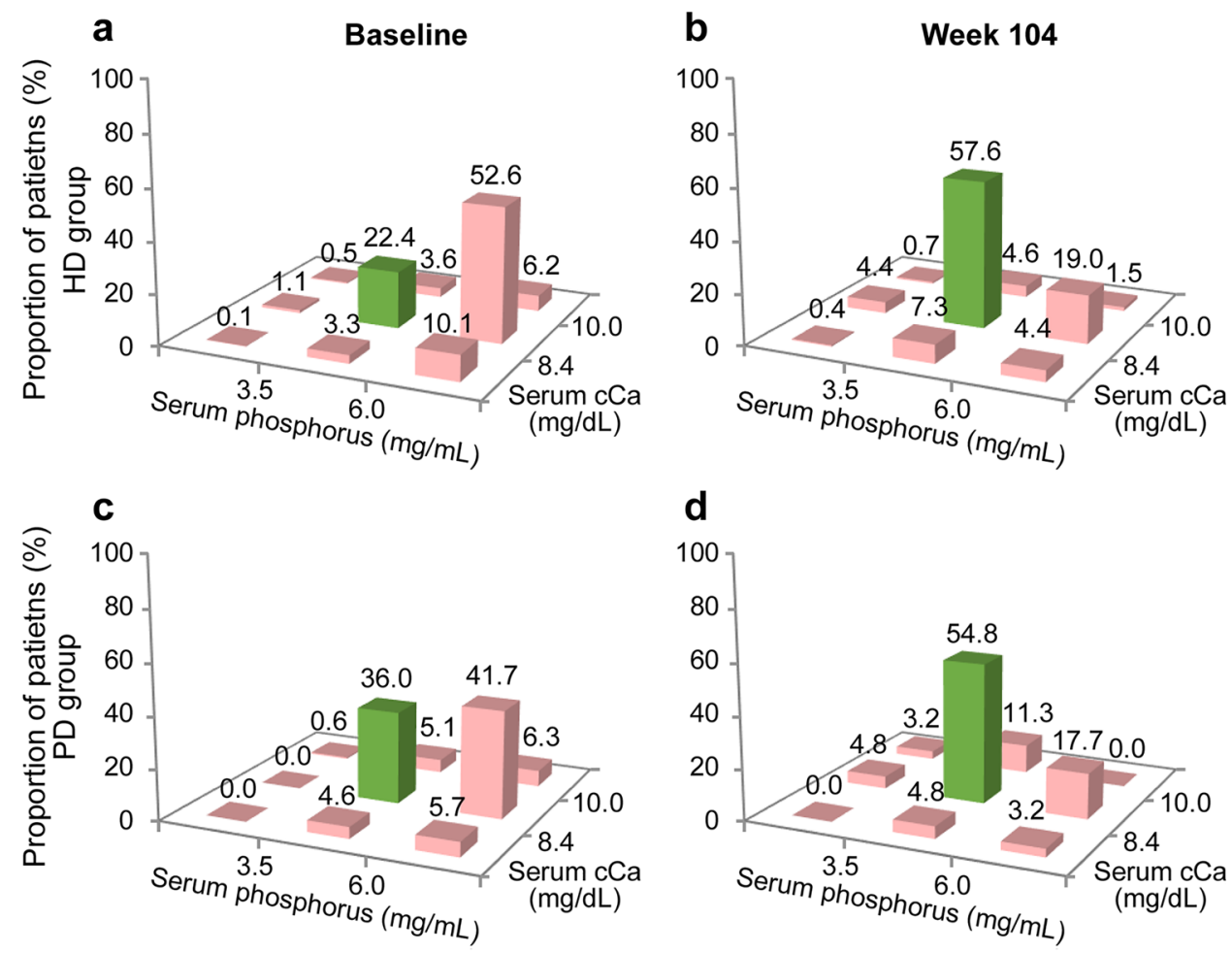

hepatic dysfunction were observed in patients with hyperferritinemia. However, further observation is needed. FC effectively controlled the serum $P$ concentration in CKD patients with hyperphosphatemia who were undergoing either hemodialysis or peritoneal dialysis or were non-dialysis-dependent.

Acknowledgements The authors thank all physicians and investigators who cooperated in this surveillance study. All statistical analyses of this study were conducted by A2 Healthcare (Tokyo, Japan), and medical writing support was provided by ASCA Corporation (Osaka, Japan).

Author contributions KY: conceived and designed the study. TH, YO, $\mathrm{RY}$, and HS: were responsible for the collection and accuracy of the data. KY, TH, YO, YM, KI, RY, HS, and NN: interpreted the data. TH, YO, YM, KI, RY, and HS: drafted the manuscript. All authors reviewed the manuscript and approved the final draft.

Data availability The datasets generated and/or analyzed during the study are available from the corresponding author on reasonable request.

\section{Declarations}

Conflict of interest Keitaro Yokoyama has received honoraria from Japan Tobacco Inc., Torii Pharmaceutical Co., Ltd., Ono Pharmaceutical Co., Ltd., and Kyowa Kirin Co., Ltd. Teruo Hashimoto, Yuri Okuda, Yu Matsumoto, Ryoichi Yamada, and Hiroyuki Susai are employees of Japan Tobacco Inc. Kyoko Ito and Noriaki Nishino are employees of Torii Pharmaceutical Co., Ltd. This surveillance study was funded by Japan Tobacco Inc. and Torii Pharmaceutical Co., Ltd.
Ethical approval This was an observational post-marketing surveillance study and was conducted in accordance with the Good Post-Marketing Study Practice (GPSP) of the Ministry of Health, Labour and Welfare in Japan. The requirement for informed consent was waived because the intervention was within general clinical practice and the data were anonymized.

Open Access This article is licensed under a Creative Commons Attribution 4.0 International License, which permits use, sharing, adaptation, distribution and reproduction in any medium or format, as long as you give appropriate credit to the original author(s) and the source, provide a link to the Creative Commons licence, and indicate if changes were made. The images or other third party material in this article are included in the article's Creative Commons licence, unless indicated otherwise in a credit line to the material. If material is not included in the article's Creative Commons licence and your intended use is not permitted by statutory regulation or exceeds the permitted use, you will need to obtain permission directly from the copyright holder. To view a copy of this licence, visit http://creativecommons.org/licenses/by/4.0/.

\section{References}

1. Go AS, Chertow GM, Fan D, McCulloch CE, Hsu CY. Chronic kidney disease and the risks of death, cardiovascular events, and hospitalization. N Engl J Med. 2004;351:1296-305.

2. Sarnak MJ, Levey AS, Schoolwerth AC, Coresh J, Culleton B, Hamm LL, et al. American heart association councils on kidney in cardiovascular disease, high blood pressure research, clinical cardiology, and epidemiology and prevention. Kidney disease as a risk factor for development of cardiovascular disease: a statement from the American Heart Association Councils on Kidney 
in Cardiovascular Disease, High Blood Pressure Research, Clinical Cardiology, and Epidemiology and Prevention. Hypertension. 2003;42:1050-65.

3. Zoccali C, Ruggenenti P, Perna A, Leonardis D, Tripepi R, Tripepi G, et al. REIN Study Group. Phosphate may promote CKD progression and attenuate renoprotective effect of ACE inhibition. J Am Soc Nephrol. 2011;22:1923-30.

4. Voormolen N, Noordzij M, Grootendorst DC, Beetz I, Sijpkens YW, van Manen JG, et al. PREPARE study group. High plasma phosphate as a risk factor for decline in renal function and mortality in pre-dialysis patients. Nephrol Dial Transpl. 2007;22:2909-16.

5. Kestenbaum B, Sampson JN, Rudser KD, Patterson DJ, Seliger SL, Young B, et al. Serum phosphate levels and mortality risk among people with chronic kidney disease. J Am Soc Nephrol. 2005;16:520-8.

6. Adeney KL, Siscovick DS, Ix JH, Seliger SL, Shlipak MG, Jenny NS, et al. Association of serum phosphate with vascular and valvular calcification in moderate CKD. J Am Soc Nephrol. 2009;20:381-7.

7. Yokoyama K, Taniguchi M, Fukagawa M. A Japanese approach for CKD-MBD. Kidney Int Suppl. 2011;2013(3):451-6.

8. Yokoyama K, Akiba T, Fukagawa M, Nakayama M, Sawada K, Kumagai Y, et al. Long-term safety and efficacy of a novel ironcontaining phosphate binder, JTT-751, in patients receiving hemodialysis. J Ren Nutr. 2014;24:261-7.

9. Yokoyama K, Akiba T, Fukagawa M, Nakayama M, Hirakata H. JTT-751 for treatment of patients with hyperphosphatemia on peritoneal dialysis. Nephron Clin Pract. 2014;128:135-40.

10. Yokoyama K, Hirakata H, Akiba T, Fukagawa M, Nakayama M, Sawada K, et al. Ferric citrate hydrate for the treatment of hyperphosphatemia in nondialysis-dependent CKD. Clin J Am Soc Nephrol. 2014;9:543-52.

11. Komatsu N, Arita K, Mitsui H, Nemoto T, Hanaki K. Efficacy and safety of ferric citrate hydrate compared with sodium ferrous citrate in Japanese patients with iron deficiency anemia: a randomized, double-blind, phase 3 non-inferiority study. Int $\mathbf{J}$ Hematol. 2021;114:8-17.

12. Yokoyama K, Fukagawa M, Akiba T, Nakayama M, Ito K, Hanaki $\mathrm{K}$, et al. Randomised clinical trial of ferric citrate hydrate on anaemia management in haemodialysis patients with hyperphosphataemia: ASTRIO study. Sci Rep. 2019;9:8877.

13. Fishbane S, Block GA, Loram L, Neylan J, Pergola PE, Uhlig $\mathrm{K}$, et al. Effects of ferric citrate in patients with nondialysisdependent CKD and iron deficiency anemia. J Am Soc Nephrol. 2017;6:1851-8.

14. Matsuo A, Iida A, Tanimoto M, Matsushita M, Miyamoto K. The utility of the phosphate binder, ferric citrate hydrate (JTT-751), about phosphorus absorption-reducing effect in normal rats. Ren Fail. 2014;36:1291-7.

15. Komatsu A, Kido Y, Hanaki K, Orui S, Nishino N, Tan M. Safety and efficacy of ferric citrate hydrate in hyperphosphatemia patients with chronic kidney disease: an interim report on postmarketing surveillance for ferric citrate hydrate. Therapeutic Res. 2019;40:457-72 (in Japanese).

16. Ban S, Suzuki S, Kubota K, Ohshima S, Satoh H, Imada H, et al. Gastric mucosal status susceptible to lanthanum deposition in patients treated with dialysis and lanthanum carbonate. Ann Diagn Pathol. 2017;26:6-9.

17. Yamamoto H, Nishi S, Tomo T, Masakane I, Saito K, Nangaku M, et al. 2015 Japanese Society for Dialysis Therapy: guidelines for renal anemia in chronic kidney disease. Ren Replace Ther. 2017;3:36.

18. Babitt JL, Eisenga MF, Haase VH, Kshirsagar AV, Levin A, Locatelli F, et al. Controversies in optimal anemia management: conclusions from a kidney disease: improving global outcomes (KDIGO) conference. Kidney Int. 2021;99:1280-95.

19. Guedes M, Muenz DG, Zee J, Bieber B, Stengel B, Massy $\mathrm{ZA}$, et al. Serum biomarkers of iron stores are associated with increased risk of all-cause mortality and cardiovascular events in nondialysis CKD patients, with or without anemia. J Am Soc Nephrol. 2021;32:2020-30.

Publisher's Note Springer Nature remains neutral with regard to jurisdictional claims in published maps and institutional affiliations. 